\title{
Recent progress of prognostic biomarkers and risk scoring systems in chronic lymphocytic leukemia
}

\author{
Xiaoya Yun ${ }^{1,2,3,4,5}$, Ya Zhang ${ }^{1,2,3,4,5^{*}}$ and Xin Wang ${ }^{1,2,3,4,5^{*}}$
}

\begin{abstract}
Chronic lymphocytic leukemia (CLL) is the most prevalent adult leukemia with high heterogeneity in the western world. Thus, investigators identified a number of prognostic biomarkers and scoring systems to guide treatment decisions and validated them in the context of immunochemotherapy. A better understanding of prognostic biomarkers, including serum markers, flow cytometry outcomes, IGHV mutation status, microRNAs, chromosome aberrations and gene mutations, have contributed to prognosis in CLL. Del17p/ TP53 mutation, NOTCH1 mutation, CD49d, IGHV mutation status, complex karyotypes and microRNAs were reported to be of predictive values to guide clinical decisions. Based on the biomarkers above, classic prognostic models, such as the Rai and Binet staging systems, MDACC nomogram, GCLLSG model and CLL-IPI, were developed to improve risk stratification and tailor treatment intensity. Considering the presence of novel agents, many investigators validated the conventional prognostic biomarkers in the setting of novel agents and only TP53 mutation status/del 17p and CD49d expression were reported to be of prognostic value. Whether other prognostic indicators and models can be used in the context of novel agents, further studies are required.
\end{abstract}

Keywords: Chronic lymphocytic leukemia, Prognosis, Prognostic biomarkers, Risk scoring systems

\section{Background}

Chronic lymphocytic leukemia (CLL) is the most prevalent adult leukemia in the western world. The disease typically occurs in older patients and presents a variable disease course. The diagnosis of CLL requires the presence of more than $5 \times 10^{9} / \mathrm{L}$ B lymphocytes in the peripheral blood, sustained at least 3 months. The leukemia cells found by blood smear are characteristically small, mature lymphocytes with a narrow border of cytoplasm and a dense nucleus lacking discernible nucleoli and having partially aggregated chromatin. CLL cells coexpress the surface antigen CD5 together with the B-cell

\footnotetext{
*Correspondence: maryzhangya@gmail.com; xinw007@126.com; xinw@sdu.edu.cn

'Department of Hematology, Shandong Provincial Hospital, Cheeloo College of Medicine, Shandong University, Jinan 250021, Shandong, China Full list of author information is available at the end of the article
}

antigens CD19, CD20 and CD23 [1]. More than 15,000 newly diagnosed cases and 4500 deaths are currently estimated in the United States [2]. However, only patients with advanced, active and symptomatic disease need therapy. Novel agents, including inhibitors of B-cell receptor signaling pathway (ibrutinib, acalabrutinib, idelalisib and duvelisib) and the inhibitor of the antiapoptotic protein BCL-2 (venetoclax), are superior compared to conventional chemoimmunotherapy (CIT) regimens. Cellular immunotherapy with chimeric antigen receptor T-cell (CAR-T) and allogeneic stem cell transplant (allo-SCT) are available for high-risk patients [39]. New challenges emerge when patients relapse on novel agents, and optimal sequencing strategies have not been established. Current clinical trials aim to deeper remissions and long-term control of CLL [2]. 
Due to the high heterogeneity of CLL, clinicians use prognostic biomarkers and risk scoring systems to guide treatment decisions. In the last over 40 years, remarkable progress has been achieved through the identification of prognostic biomarkers capable of predicting survival and disease progression and reflecting the response to therapy. The conventional prognostic biomarkers and risk scoring systems have been validated in the CIT era. However, the prognostic value of the biomarkers and risk scoring systems in the context of novel agents needs further studies. In this review, we summarize prognostic biomarkers and risk scoring systems to identify the prognosis of CLL patients and discuss the possibility of using them in the era of novel agents.

\section{Prognostic biomarkers in CLL}

The last three decades have generated a plethora of potential biomarkers. They range from serum markers to immunophenotypic markers, IGHV mutation status, chromosome aberrations, gene mutations, microRNAs and others. The application of these biomarkers in the context of novel agents have been studied in a series of studies. The recognized prognostic biomarkers in CLL are present in Table 1.

\section{Serum markers}

The serological test, which plays a crucial role in both diagnosis and evaluation of prognosis in CLL, is standard and inexpensive. Lymphocyte doubling time (LDT), serum beta2-microglobulin $(\mathrm{s}-\beta 2 \mathrm{M})$, serum thymidine kinase (s-TK) and lactic dehydrogenase (LDH) are the most common conventional serum markers in CLL and predict poor outcomes. LDT has been used as a

Table 1 Prognostic biomarkers in chronic lymphocytic leukemia

\begin{tabular}{ll}
\hline Category & Prognostic biomarkers \\
\hline Serum markers & $\begin{array}{l}\text { Thymidine kinase, beta2-microglobulin, lactic } \\
\text { dehydrogenase, lymphocyte doubling time, } \\
\text { autocrine interleukin-6, copper, free light } \\
\text { chains, lipoprotein lipase, c-reaction protein, } \\
\text { BAFF, TACI, APRIL, BCMA, EZH2 }\end{array}$ \\
Immunophenotypic & CD38, ZAP70, CD49d, CD26, CD54, CD44, \\
markers & CD52, CD69, CD25, CD5, CD95, CD39, \\
IGHV mutation status & CD11c, CD36, CD150 \\
Chromosome & Del13, U-CLL \\
aberrations & del19p21, del10q23, total or partial \\
& trisomies of chromosomes 3, 8, 18, 19 \\
and duplications in 2p24 \\
Gene mutations & TP53, ATM, NOTCH1, BIRC3, MYD88, \\
& SF3B1, FBXWY, POT1, CHD2, RPS15, IKZF3, \\
& ZNF292, ZMYM3, ARID1A, PRPN11, COBLL1, \\
& LPL, ZAP70 \\
Non-coding RNA and & MiR-15a, miR-16-1, miR-155, miR-29a, miR-29b, \\
Others & miR-34a, miR-125a, miR-155, miR-181b, \\
& I-tRF-GlyCCC \\
\hline
\end{tabular}

prognostic parameter for more than 30 years. LDT $\leq 12$ months predicts poor prognosis while LDT $>12$ months correlates with a long treatment-free period and survive [10]. S- $\beta 2 \mathrm{M}$ level and s-TK level were reported as independent predictors of progression-free survival (PFS) of CLL more than 20 years ago [11]. S- $\beta 2 \mathrm{M}$ was widely used to improve risk stratification and retained independent prognostic value in several multiparameter scores [12-21]. Elevated s-TK level, which relates to shorter LDT and IGHV unmutated status, indicates the high risk of CLL patients and predicts disease progression [22]. LDH is an indicator of time to first treatment (TTFT) and associated with shorter PFS, overall survival (OS) and Richter's transformation [23]. It is still of prognostic value in patients with trisomy 12 [24].

Besides, some other serum markers have also been suggested in recent years. The measurement of autocrine interleukin-6 (IL-6) could be a useful approach to predict clinical outcomes [25]. Higher serum copper level predicts a shorter time to start treatment and poor response to treatment. It is significantly associated with increased expressions of CD38 and ZAP70 [26]. Increased serum free light chains (sFLC) correlates with $s-\beta 2 M$, serum albumin, hemoglobin, abnormal LDH and regards to shorter time to treatment and OS [27]. Lipoprotein lipase (LPL) is an indicator of OS for CLL patients, while LPL mRNA expression, correlating with IGHV mutation status, also has a significant impact on survival [28]. Increased C-reaction protein (CRP) was approved as a predictor for shorter survival and associated with the development of second cancers [29]. The levels of serum B cell activator factor (BAFF), transmembrane activator and calcium-modulator and cyclophilin ligand interactor (TACI), the proliferation-inducing ligand APRIL, and Bcell maturation antigen (BCMA) were reported as novel predictors for OS [30, 31]. Enhancer of zeste homolog 2 (EZH2), a catalytic subunit of the initiation complex polycomb repressive complex 2 (PRC2), which was reported to mediate normal $\mathrm{B}$ cell and $\mathrm{T}$ cell lymphogenesis and modulate pathogenesis of lymphoid malignancies, is associated with more aggressive course in CLL [32, 33].

\section{Immunophenotypic markers}

Based on the flow cytometry, CD38 and ZAP70 expression were validated to be accurate prognostic indicators of CLL [34]. Both of them can predict TTFT in the Binet 0 stage [35]. CD38 positivity, which is associated with other unfavorable factors such as higher $\mathrm{s}-\beta 2 \mathrm{M}$ level and high-risk karyotypes, predicts the resistance of treatment, hepatomegaly and shorter survival [36, 37]. ZAP70 expression is associated with disease progression and is a predictor of Ritcher's syndrome (RS) [38, 39]. CD38 positive identifies unmutated IGHV clones, while 
ZAP70 is a better indicator for IGHV mutation status [37]. However, another study investigated that it can predict treatment-free survival (TFS) and PFS in CLL patients but it was only in the absence of high-risk cytogenetic factors that is ZAP70 associated with IGHV mutation status [40]. CD49d expression is a strong independent factor of survival and treatment need. It is associated with the presence of lymphadenopathy at diagnosis and the development of lymphadenopathy during the course of the disease. CD49d drives disease progression and its expression pattern should also be considered to improve prognostic impact [41]. Besides, other $C D$ markers may be associated with clinical symptoms and outcomes. CD26 expression is an independent indicator of time to treatment in CLL patients [42]. CD54, CD44, CD52, CD69, CD25, CD5, CD95, CD39, CD11c and CD36 expressions are indicators of poor outcomes, while CD150 predicts favorable course [36, 43].

\section{IGHV mutation status}

The IGHV mutation status plays a pivotal role in the prognosis of CLL. According to the IGHV mutation status, patients can be divided into mutated CLL (M-CLL) patients and unmutated CLL (U-CLL) patients. Unmutated IGHV status, relating to shorter LDT and CD38 overexpression, is associated with a more aggressive course of CLL and predicts shorter TTFT in treatment-naïve patients, while M-CLL patients have better outcomes [44-47]. However, the correlation between U-CLL and CD38 expression was not found in another study [48]. Higher levels of CD47 are also related to U-CLL [49]. Compared to M-CLL, U-CLL is 4 times more likely to develop Richter syndrome (RS) [38]. In CLL patients with isolated del13q, U-CLL has shorter TTFT than M-CLL, whereas there was no significant difference in U-CLL and M-CLL in patients with tri12 [50]. According to BCR IG, patients can be assigned into subsets while the largest stereotyped subsets are \#1, \#2, \#4 and \#8. U-CLL subset \#2 cases had shorter TTFT and TTNT than those in M-CLL, so the BCR IG subset \#2 appeared as an independent prognostic factor [51]. Besides, a novel prognostic biomarker Fc receptor-like 2 (FCRL2) of low-risk CLL has prognostic value in CLL and predicts TTFT and OS [52]. The new prognostic biomarker was also able to further refine and extend prognosis in M-CLL patients.

\section{Chromosome aberrations}

Fluorescence in situ hybridization (FISH), karyotype analysis and next-generation sequencing have been widely used in recent years in the diagnosis and risk stratification of CLL, making treatment decisions and designing clinical trials. Based on the data from SEER POC, Erlene $\mathrm{K}$ et al. proposed a real-world study and compared 1008 patients diagnosed in 2008 with 1367 patients diagnosed in 2014 [53], the most common chromosomal aberrations are deletions of the long arm of chromosome 13 (del13q), trisomy 12 (tri12), deletions of the long arm of chromosome 11 (del11q), and deletions of the short arm of chromosome 17 (del17p) (shown in Fig. 1). Besides, the performance of FISH test, karyotype analysis, and IGHV mutation test were all increased (shown in Fig. 2). The performance of these tests refines the risk stratification of CLL. Both chromosomal aberrations and gene mutations improve the prognostication of CLL patients.

Del13q, specifically involving band $13 \mathrm{q} 14$ on which miR-15a and miR-16a are located, seems to be the most frequently observed cytogenetic aberration in CLL and associated with a good prognosis [54, 55]. Patients with isolated del13q need treatment sooner and have a shorter OS if the cells with del13q $\geq 60 \%$ [56]. Both deletions of $13 \mathrm{q} 14$ and translocations with concomitant deletion at $13 \mathrm{q} 14$ can predict the unfavorable outcome of CLL [57]. A defective 5methylcytosine (5-mCyt) status has association with a higher percentage of del13q, which suggests an aggressive process [58].

Tri12 is the second most frequent recurrent chromosomal aberrations in CLL and reported as an intermediate-risk cytogenetic aberration in newly diagnosed CLL patients [54]. A high proportion of cells with tri12 predicts worse outcomes [59]. CLL patients with tri12 present clinical and biological heterogeneity with the presence of additional genomic aberrations, such as trisomy 19 [60]. French Innovative Leukemia Organization (FILO) working group hosted a prospective study based on mutational and cytogenetic analysis of 188 CLL patients with tri12 [61]. The study showed that additional trisomies combined with tri12 were related to longer TTFT in Binet A stage patients and with a low risk of relapse [61].

Del11q is correlated with a worse prognosis. Patients with del11q have a shorter TFS but longer OS [62]. The lower frequency of del11q predicts the better outcome and the low frequency of gene mutations [63]. For the patients after allogeneic hematopoietic cell transplantation (allo-HCT), del11q, as well as del17q, can predict worse PFS and OS [64].

Del17p is found in $5-8 \%$ chemotherapy-naïve patients and associated with a dismal prognosis $[2,65]$. As have been noted, del17p might influence the elimination of rituximab, which may explain the treatment resistance or rapid relapse [65]. The percentage of del17p cells has an impact on the prognosis of CLL patients, and the low percentage of del17p cells predicts a better TTFT [66]. However, another study revealed that neither del17p, mutated p53, nor complex karyotypes is 


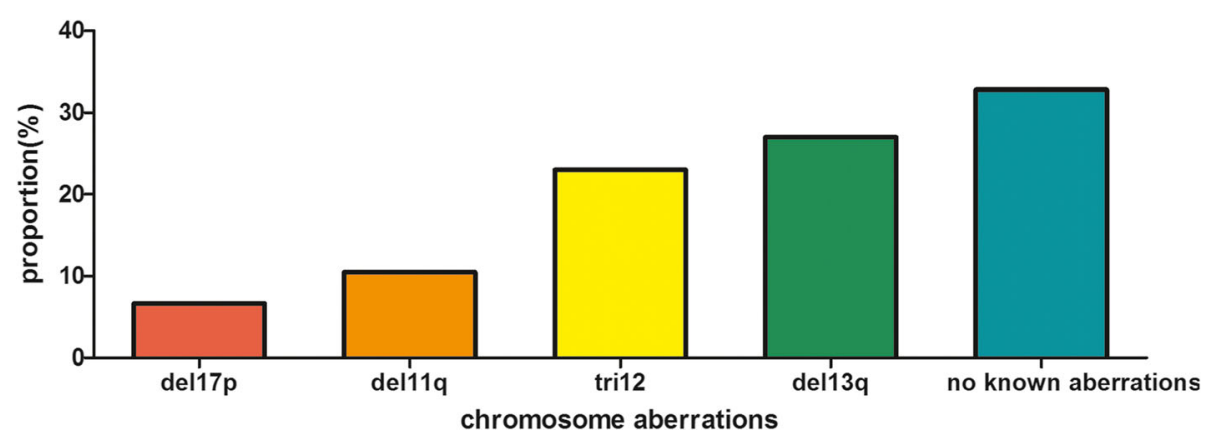

Fig. 1 The percentage of common chromosome aberrations tested by fluorescence in situ hybridization

associated with TTFT, which suggests that they have limited roles in early CLL patients but may take effect in relapsed disease [47]. Besides chromosome aberrations above, del6q, del9p21, del10q23, total or partial trisomies of chromosomes $3,8,18,19$, and duplications in 2 p24 also have an impact on prognosis in CLL [67].

Complex karyotype (CK), defined by the presence of at least three cytogenetic abnormalities, is associated with poor outcomes [68]. Nevertheless, not all CKs are equivalent [69]. Panagiotis Baliakas et al. proposed a study that stratified CK patients into three subgroups based on whether they were carrying 3 or 4 or $\geq 5$ abnormalities and defined them as low, intermediate and high CK, respectively [70]. According to this study, high-CK was associated with unfavorable outcomes, independently of the SHM and TP53 status.

\section{Gene mutations}

In addition, gene mutations also play a pivotal role in CLL prognosis. The gene mutations examined by next- generation sequencing are associated with unmutated IGHV genes, CD 38 expression, and CK [71]. There have been 44 recurrently mutated genes and 11 recurrent somatic copy number variations identified in recent years [72].

NOTCH1 mutation, which is a predictor for advanced disease, is associated with tri12 [73]. The gene ATM, located on band 11q23, is associated with poor outcomes. Patients with del11q tend to harbor mutated ATM. Both del11q and mutated ATM may predict reduced survival [74]. BIRC3 mutation, also located on 11q and always coexisted with ATM deletion, erects a prognostic role in CLL patients [75]. The prominent tumor suppressor gene TP53 is located in the band $17 \mathrm{p} 13$. TP53 disruption relates to unfavorable prognosis in CLL patients [76]. The overexpression of a novel oncogene maternal embryonic leucine zipper kinase (MELK) predicts inferior survival in CLL and correlates with deletion of $17 \mathrm{p} 13$, as well as higher WBC count, advanced stage, elevated $\mathrm{LDH}$, increased $\beta 2-\mathrm{M}$, unmutated IGHV status and positive ZAP70 [77].

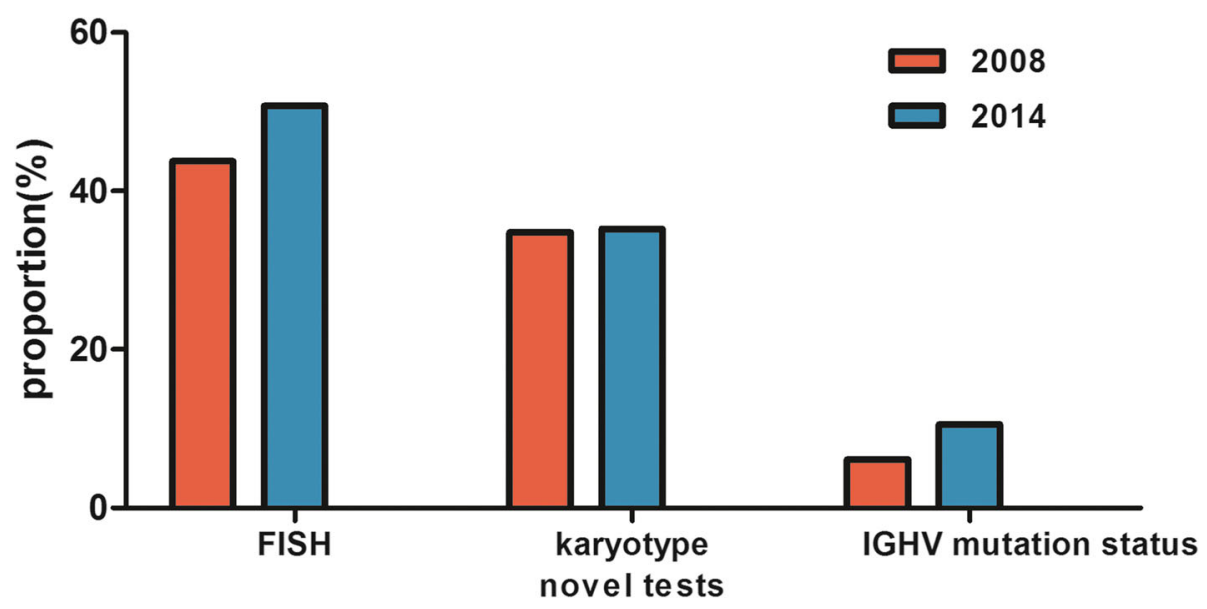

Fig. 2 Comparison of fluorescence in situ hybridization (FISH), karyotype analysis and IGHV mutation test between 2008 and 2014 
Besides, MYD88, SF3B1, FBXWY, POT1, CHD2, RPS15, IKZF3, ZNF292, ZMYM3, ARID1A, and PTPN11 are also of the significant value of predicting the outcome of CLL patients [2]. NOTCH1 is the most frequently mutated gene, followed by XPO1, SF3B1, FBXW7, TP53, and MYD88 [78]. In treatment-naïve patients, mutated ATM, NOTCH1, and SF3B1 is correlated to shorter TTFT [47]. COBLL1, LPL, and ZAP70 gene expression is correlated to IGHV mutation status and is a predictor for OS and TTFT of CLL patients [79]. The number of mutations also has an impact on the prognosis. More than 2 mutations are independently associated with a shorter TTFT [71]. Genetic dynamics in untreated CLL patients suggests that monitoring variant allele frequency of a special gene panel may predict disease progression [80].

\section{MicroRNAs and others}

MicroRNAs (miRNAs) are a group of small noncoding RNAs and play a crucial role in the regulation of gene expression. Human cancer is associated with miRNA expression, including CLL [81-83]. MiR-15a and miR-16-1, located on 13q14, were the earliest miRNAs used in the prognosis of CLL. They behave as tumor suppressors in CLL and are associated with TTFT [82]. More and more miRNAs were proved to have prognostic value in CLL. MiR-34a, targeting ZAP70 mRNA expression, is associated with the chemotherapy-refractory disease [84]. The downregulation of miR-34a and miR-125a upregulation was found to be associated with RS [85]. MiR-155 was reported as the most prevalent oncomiR in B-cell malignancies and revealed as a poor predictor for CLL, as well as an indicator to predict the therapy response [84, 86]. MiR-29a and miR-29b overexpression leads to aggressive CLL, as well as miR-155 [87]. MiR-1292 methylation is associated with poor survival in CLL [88]. The expression of miRNAs also correlates with ethnicity. A study in the Chinese Uygur and Han populations revealed that the expression levels of miR-155, miR-29b, miR-181a, and miR-181b were associated with IGHV mutation and the low expression levels of miR-34a, miR-29b and miR-181b may be affected by p53 abnormality [89]. Besides miRNA, other non-coding RNAs were also estimated to predicts outcomes of CLL [90]. For example, I-tRF-GlyCCC, a fragment originating from tRNAs bearing the glycine anticodon CCC, was found unfavorable prognostic value in CLL patients [91].

All of the biomarkers above have prognostic value to evaluate the risk of disease progression and death. But only del 17p/ TP53 mutation has definitive predictive value related to the response of specific therapy. NOTCH1 mutation, associated with unfavorable response of anti-CD20 therapy, has potential predictive value to tailor clinical decision [92]. Other proposed predictive biomarkers were also reported, including IGHV mutation status, CD49d, CK and miRNA. (shown in Table 2).

\section{Risk staging systems in CLL}

Based on the study of prognostic factors, the investigators integrated age, gender, performance status of patients and the prognostic biomarkers above to make risk stratification more precise and robust. For the purpose of identifying the risk groups, the classic prognostic staging systems, such as Rai and Binet staging systems, MDACC nomogram, GCLLSG model and CLL-IPI, were published. It can be seen that the risk factors altered from the combination of clinical features and laboratory features to the combination of clinical and laboratory features with cytogenetic features. (shown in Fig. 3) On the base of these models, more risk scoring systems were reported to assist in risk stratification. The detailed information about prognostic models can be seen in Table S1.

Rai and Binet staging systems, published in 1975 and 1981 separately, were the most widely used conventional staging systems in the clinical practice. The two staging systems based on the physical examination, including peripheral blood, lymph nodes, liver, spleen, and bone marrow [93, 94]. In comparison between the Rai stage and the Binet stage, it seems that the Rai stage is more accurate in patients with an excellent prognosis [95]. They used inexpensive and standard tools to identify 3 major prognostic subgroups. Furthermore, they are the basis of other prognostic models. However, the two staging systems fail to discriminate amongst patients at an early stage those who will experience an aggressive disease course. In addition, they do not incorporate the newly published biological characters, such as FISH and next-generation sequencing outcomes. Otherwise, the two staging systems have limited predictive power rewarding the response to therapy.

After Rai and Binet stage, MD Anderson Cancer Center (MDACC) group proposed a prognostic nomogram to predict OS for CLL patients, which combined age, $\beta 2 \mathrm{M}$, absolute lymphocyte count, Rai stage and number of involved lymph node group in 2007 [12]. The nomogram can be used in early stage patients but the effect to therapy was not validated. Thus, Stefano Molica et al. modified the MDACC nomogram by changing cutoff to predict TTFT in Binet A stage patients in 2010 [13]. In addition, Pietro Bulian et al. integrated del17p and IGHV mutation status into the comprehensive model which includes Binet stage, $\beta 2 \mathrm{M}$, age, and gender to estimate OS in 2012 [14]. The new model made up the deficiency that the MDACC nomogram did not include the biological and cytogenetic factors. 
Table 2 Clinical significance of predictive biomarkers in chronic lymphocytic leukemia

\begin{tabular}{ll}
\hline Predictive biomarkers & Clinical significance \\
\hline Del 17p/ TP53 mutation & $\begin{array}{l}\text { Predicts poor response to } \\
\text { chemo-immunotherapy } \\
\text { NOTCH1 mutation }\end{array}$ \\
Predicts poor response to \\
anti-CD20 therapy \\
Inhibits cell trafficking in the \\
setting of novel BCR target \\
therapy \\
Gives its potential for \\
Iong-term remission in the use \\
of BCR in younger, fit patients \\
with M-IGHV \\
Predict poor response to \\
chemo-immunotherapy when \\
complex karyotypes with major \\
structural abnormalities. \\
MiR-34a: associates with \\
chemotherapy-refractory disease \\
MiR-155: predicts therapy response
\end{tabular}

In 2014, GCLLSG published a new prognostic score. The new prognostic score incorporated sex, age, Eastern Cooperative Oncology Group (ECOG) status, del17p, del11q, IGHV mutation status, s- $\beta 2 \mathrm{M}$ and $\mathrm{s}-\mathrm{TK}$, which classified 4 risk categories [15]. The new prognostic score was validated in newly diagnosed CLL patients from the Mayo clinic [96]. It made up the deficiency of the Rai and Binet staging systems which lacked the new prognostic biomarkers. However, IGHV mutation status and s-TK level are not widely available. To reinforce the management of early stage CLL patients without s-TK level, Stefano Molica et al. proposed a modified version which not included s-TK assessment [16]. Indeed, it was also validated to predict the TTFT of CLL patients in the early stage with other 7 independent prognostic factors.

The CLL International Prognostic Index (CLL-IPI), the most widely used scoring system in clinical management, combines both clinical parameters and cytogenetic factors into a prognostic model in 2016. It contains 5 independent prognostic factors: TP53 status, IGHV mutational status, $s-\beta 2 \mathrm{M}$ concentration, clinical stage and age and identified 4 risk groups [97]. Compared with the nomogram proposed by the MDACC group, the CLL-IPI included cytogenetic abnormalities and was confirmed higher prognostic value in both OS and TTFT for newly diagnosed patients $[12,98,99]$. It predicts both PFS and OS and can be used in varieties of CIT approaches [100]. However, IGHV mutational status was only available in $10.1 \%$ CLL patients in 2014 in the United States [53]. Due to the correlation between LDT and IGHV mutational status, Deepesh P. Lad et al. created the modified CLL International Prognostic Index (CLL-LIPI), replacing IGHV unmutated status to LDT < 6 months and maintaining the original score of CLL-IPI [18]. It shows a comparable prognosis of OS with CLLIPI. Compared with IGHV mutation status, LDT is more inexpensive and available. In the absence of IGHV mutational status, the CLL-LIPI still plays a crucial role in identifying the prognosis of CLL patients. Of note, the single-center study, which enrolled only 218 patients, can predict TTFT but not TTNT. In addition, CLL-IPI has a higher value in predicting the overall outcome [101]. To evaluate CLL-IPI in R/R CLL with novel therapy, Jacob D. Soumerai et al. found that the value of each prognostic indicator might be different compared with untreated CLL [19]. Thus, they modified cutoff for

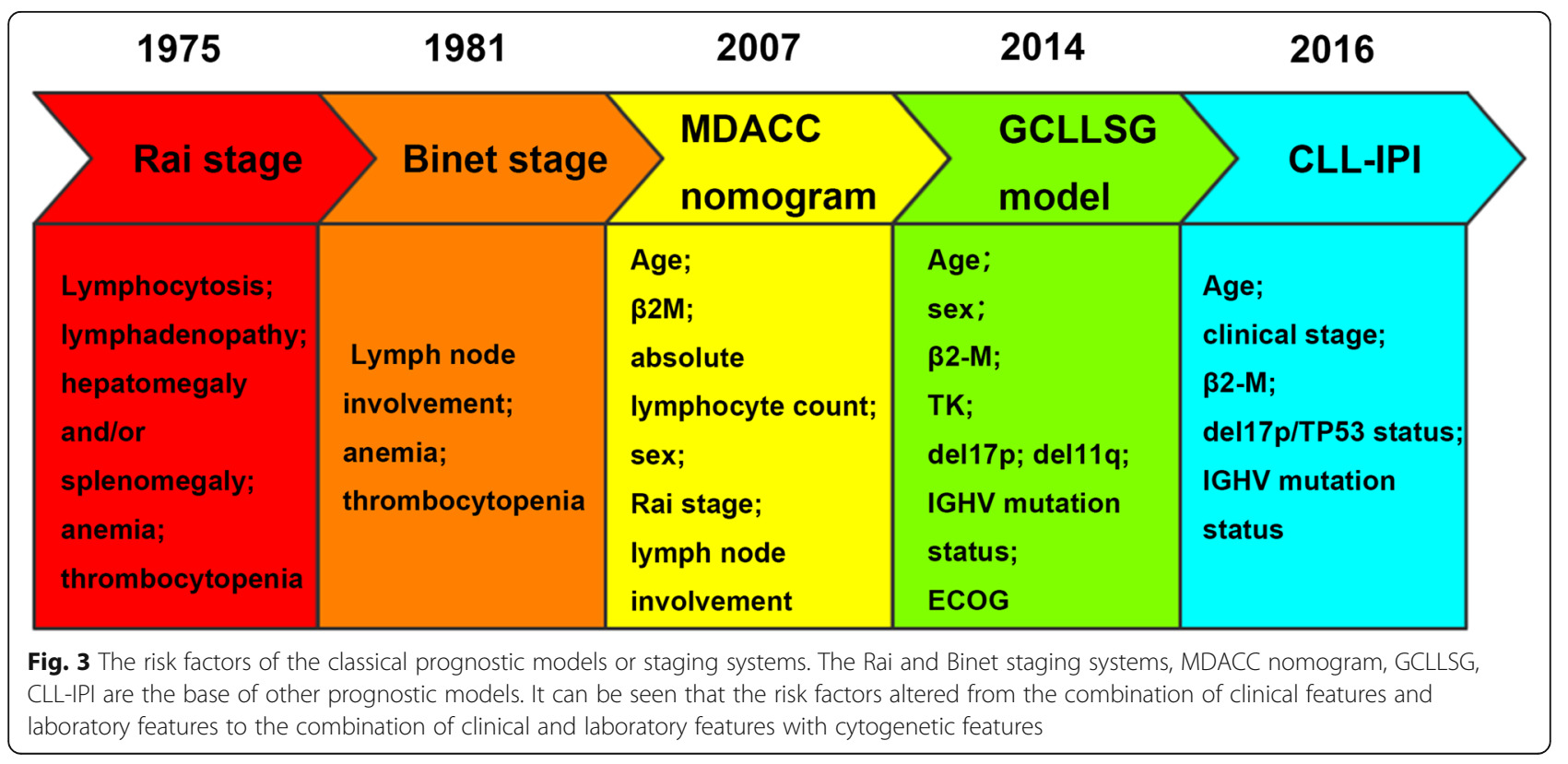


the clinical stage and assigned 1 point to each indicator. The modified score may improve the assessment of $R / R$ CLL prognosis but is restricted to the CLL-IPI variables.

Based on the classic staging systems or prognostic models above, there have been other prognostic models reported in recent years. For patients with R/R CLL, Jacob D Soumerai et al. developed a prognostic risk score (BALL), which consisted of 4 factors, including s- $\beta 2 \mathrm{M}, \mathrm{LDH}$, hemoglobin and time from initiation of last therapy and separated patients into 3 subgroups [20]. This risk score reliably identifies treated patients with an increased risk of death and can be used to stratify patients in future clinical trials.

For patients after reduced-intensity conditioning allogeneic hematopoietic cell transplantation (RIC HCT), JR Brown et al. proposed a model to predict outcomes for patients undergoing reduced-intensity allogeneic stem cell transplantation in 2013 [102]. It incorporated remission status, LDH, comorbidity score, and lymphocyte count and separated patients into 4 subgroups. It can predict both PFS and OS for patients.

For patients with early stage, Manuela A. Hoechstetter et al. raised a prognostic model (CLL1-PM) for newly diagnosed CLL patients in Binet A stage by a multicenter, prospective CLL1 trial of the German CLL study group [21]. Del17p, unmutated IGHV, del11q, s- $\beta 2 \mathrm{M}>3.5 \mathrm{mg} /$ $\mathrm{dL}, \mathrm{LDT}<12$ months and age $>60$ years were identified as 6 independent factors and associated with OS and TTFT. These factors were integrated into CLL1-PM and separated patients into 4 risk subgroups. Although the new prognostic model has advantages to the management of newly diagnosed patients in the early stage, the outcomes of next-generation sequencing were not included.

There are other models that only incorporated two risk factors. Julio Delgado et al. built a model comprising IGHV mutation status and FISH cytogenetics (del11q and del17p) and separated patients into 3 risk groups [103]. It was validated in two independent cohorts and had similar discriminatory with CLL-IPI. Thus, the model may simplify the risk stratification in clinical management. Tamar Tadmor et al. proposed a new risk model based on heavy+light chains (HLC) and IgG subclasses to predict TTFT [104]. The model separated patients into 3 subgroups according to the numbers of risk factors and patients with 2 risk factors are of ultra-highrisk with a median TTFT of only 1.3 months. This study demonstrated the potential for the use of HLC and FLC immunoassays in future prognostication. Although all of the models above need to be further validated, they can improve the clinical management for CLL patients and help design clinical trials better.

However, the emergence of novel agents, such as Bruton tyrosine kinase (BTK) inhibitor ibrutinib, acalabrutinib and zanubrutinib, the phosphoinositide 3-kinase (PI3K) inhibitor idelalisib, the BCL-2 inhibitor venetovlax and other novel agents targeting different pathways, revolutionized the treatment and prognosis [105-107]. Targeting the promising biomarker EZH2, tazemetostat (EPZ6438) shows antitumor activity in patients with refractory B-cell non-Hodgkin lymphoma [33, 108, 109]. Combination therapy with EZH2 inhibitors improves the efficacy of responses to signaling inhibitors [32]. In era of novel targeted agents, validations of the traditional prognostic parameters are warranted. Of note, many prognostic indicators validated in the era of CIT, including del17p/TP53 mutation, del11q, and unmutated IGHV status, are not of prognostic value in patients with relapsed/refractory CLL undergoing target therapy [110]. Adam S. Kittai et al. reviewed literature and concluded that high-risk features did not have the same impact on clinical outcomes in the era of the novel agent when compared with CIT, and only del17p/TP53 mutation and CD49d expression still predicted the inferior outcomes [111]. Patients with TP53 mutation undergoing ibrutinib \pm rituximab have shorter PFS and OS, while patients undergoing idelalisib have shorter OS [112]. Del17p plays a significant role in predicting PFS in patients undergoing obinutuzumab + venetoclax [113]. In ibrutinib-treated patients, CD49d predicts reduced lymphocytosis and inferior nodal response and behaves as an independent predictor of shorter PFS [114]. The minimal residual disease (MRD) level is a prognosis indicator for PFS and OS of CLL patients with CIT [115]. Achieving MRD negativity may provide a more significant benefit for risk change, but the prognostic value of MRD in patients with novel agents needs more validated [116]. Indeed, the prognostic value of traditional biomarkers needs further study.

\section{Conclusion}

In summary, there are a series of prognostic indicators and models can be used in the context of CIT. A better understanding of prognostic and predictive biomarkers helps to contribute to predicting survival and response to therapy in CLL. The classic scoring systems, such as the Rai and Binet staging systems, MDACC nomogram, GCLLSG model and CLL-IPI, incorporated them to improve risk stratification and guide treatment decisions. In the setting of novel therapy, current studies reported that only del 17p/TP53 mutation and CD49d expression still have prognostic value. The prognostic value of other biomarkers and models in the context of novel agents needs further studies.

\section{Supplementary information}

Supplementary information accompanies this paper at https://doi.org/10. 1186/s40364-020-00222-3.

Additional file 1: Table S1. Prognostic models or staging systems in chronic lymphocytic leukemia patients. 


\section{Abbreviations}

CLL: chronic lymphocytic leukemia; CIT: chemoimmunotherapy; CAR$\mathrm{T}$ : chimeric antigen receptor T-cell; allo-SCT: allogeneic stem cell transplant; s-TK: serum thymidine kinase; PFS: progression-free survival; CLL-IPI: chronic lymphocytic leukemia international prognostic index; GCLLSG: German chronic lymphocyte leukemia study group; LDH: lactic dehydrogenase; TTFT: time to first treatment; OS: overall survival; tri12: trisome 12; LDT: Iymphocyte doubling time; IL-6: interleukin-6; sFLC: serum free light chains; LPL: lipoprotein lipase; IGHV: immunoglobulin heavy chain variable region; CRP: C-reaction protein; RS: Ritcher's syndrome; TFS: treatment-free surviaval; miRNA: microRNA; BAFF: B cell activator factor;

TACl: transmembrane acivator and calcium-modulator and cyclophilin ligand interactor; BCMA: B-cell maturation antigen; EZH2: enhancer of zeste homolog 2; PRC2: polycomb repressive complex 2; FISH: fluorescence in situ hybridization; del13q: deletions of the long arm of chromosome 13; 5mCyt: 5-methylcytosine; del11q: deletions of the long arm of chromosome 11; allo-HCT: allogeneic hematopoietic cell transplantation; FILO: French Innovative Leukemia Oraganization; TTNT: time to next treatment del17p: deletions of the short arm of chromosome 17; MELK: maternal embryonic leucine zipper kinase; CK: complex karyotype; MDACC: MD Anderson Cancer Center; ECOG: Eastern Cooperative Oncology Group; RIC $\mathrm{HCT}$ : reduced-intensity conditioning allogenetic hematopoietic cell transplantation; BTK: Bruton tyrosine kinase; PI3K: phosphoinositide 3-kinase; MRD: minimal residual disease

\section{Acknowledgements}

None.

\section{Authors' contributions}

Xiaoya Yun wrote the initial manuscript. Xin Wang and Ya Zhang revised the manuscript. All authors read and approved the final manuscript.

\section{Funding}

This study was funded by National Natural Science Foundation (No. 81270598, No. 81473486, and No. 81770210); Key Research and Development Program of Shandong Province (No.2018CXGC1213); Technology Development Projects of Shandong Province (No. 2017GSF18189); Taishan Scholars Program of Shandong Province; Shandong Provincial Engineering Research Center of Lymphoma; Key Laboratory for Kidney Regeneration of Shandong Province; Academic promotion programme of Shandong First Medical University; Shandong Provincial Hospital Youth Talent Plan; Shandong Provincial Hospital Research Incubation Fund.

\section{Availability of data and materials}

Not applicable.

\section{Ethics approval and consent to participate}

Not applicable.

\section{Consent for publication}

Not applicable.

\section{Competing interests}

The authors declare that they have no competing interests.

\section{Author details}

${ }^{1}$ Department of Hematology, Shandong Provincial Hospital, Cheeloo College of Medicine, Shandong University, Jinan 250021, Shandong, China. ${ }^{2}$ Department of Hematology, Shandong Provincial Hospital Affiliated to Shandong First Medical University, No.324, Jingwu Road, Jinan 250021, Shandong, China. ${ }^{3}$ School of Medicine, Shandong University, Jinan 250012, Shandong, China. ${ }^{4}$ Shandong Provincial Engineering Research Center of Lymphoma, Jinan 250021, Shandong, China. ${ }^{5}$ National clinical research center for hematologic diseases, Jinan 250021, Shandong, China.

Received: 6 July 2020 Accepted: 26 August 2020

Published online: 07 September 2020

\section{References}

1. Hallek M, Cheson BD, Catovsky D, Caligaris-Cappio F, Dighiero G, Döhner $H$, Hillmen P, Keating M, Montserrat E, Chiorazzi N, et al. iwCLL guidelines for diagnosis, indications for treatment, response assessment, and supportive management of CLL. Blood. 2018;131(25):2745-60.

2. Hallek M. Chronic lymphocytic leukemia: 2020 update on diagnosis, risk stratification and treatment. Am J Hematol. 2019;94(11):1266-87.

3. lovino L, Shadman M. Novel therapies in chronic lymphocytic leukemia: a rapidly changing landscape. Curr Treat Options in Oncol. 2020;21(4):24.

4. Perini GF, Ribeiro GN, Pinto Neto JV, Campos LT, Hamerschlak N. BCL-2 as therapeutic target for hematological malignancies. J Hematol Oncol. 2018; 11(1):65.

5. Liu D. CAR-T "the living drugs", immune checkpoint inhibitors, and precision medicine: a new era of cancer therapy. J Hematol Oncol. 2019;12(1):113.

6. Hardy-Abeloos C, Pinotti R, Gabrilove J. Ibrutinib dose modifications in the management of CLL. J Hematol Oncol. 2020;13(1):66.

7. Elgamal OA, Mehmood A, Jeon JY, Carmichael B, Lehman A, Orwick SJ, Truxall J, Goettl VM, Wasmuth R, Tran M, et al. Preclinical efficacy for a novel tyrosine kinase inhibitor, ArQule 531 against acute myeloid leukemia. J Hematol Oncol. 2020;13(1):8

8. Zou Y, Xu W, Li J. Chimeric antigen receptor-modified T cell therapy in chronic lymphocytic leukemia. J Hematol Oncol. 2018;11(1):130.

9. Huang R, Li X, He Y, Zhu W, Gao L, Liu Y, Gao L, Wen Q, Zhong JF, Zhang C, et al. Recent advances in CAR-T cell engineering. J Hematol Oncol. 2020;13(1):86.

10. Montserrat E, Sanchez-Bisono J, Vinolas N, Rozman C. Lymphocyte doubling time in chronic lymphocytic leukaemia: analysis of its prognostic significance. Br J Haematol. 1986;62(3):567-75.

11. Hallek M, Wanders L, Ostwald M, Busch R, Senekowitsch R, Stern S, Schick HD, Kuhn-Hallek I, Emmerich B. Serum beta(2)-microglobulin and serum thymidine kinase are independent predictors of progression-free survival in chronic lymphocytic leukemia and immunocytoma. Leuk Lymphoma. 1996; 22(5-6):439-47.

12. Wierda WG, O'Brien S, Wang X, Faderl S, Ferrajoli A, Do KA, Cortes J, Thomas D, Garcia-Manero G, Koller C, et al. Prognostic nomogram and index for overall survival in previously untreated patients with chronic lymphocytic leukemia. Blood. 2007;109(11):4679-85.

13. Molica S, Mauro FR, Callea V, Giannarelli D, Lauria F, Rotoli B, Cortelezzi A, Liso $V$, Foà $R$. The utility of a prognostic index for predicting time to first treatment in early chronic lymphocytic leukemia: the GIMEMA experience. Haematologica. 2010;95(3):464-9.

14. Bulian P, Rossi D, Forconi F, Del Poeta G, Bertoni F, Zucca E, Montillo M, Pozzato G, D'Arena G, Efremov DG, et al. IGHV gene mutational status and $17 p$ deletion are independent molecular predictors in a comprehensive clinical-biological prognostic model for overall survival prediction in chronic lymphocytic leukemia. J Transl Med. 2012;10:18.

15. Tam CS, Seymour JF. A new prognostic score for CLL. Blood. 2014; 124(1):1-2.

16. Molica S, Giannarelli D, Mirabelli R, Levato L, Russo A, Linardi M, Gentile M, Morabito F. Unavailability of thymidine kinase does not preclude the use of German comprehensive prognostic index: results of an external validation analysis in early chronic lymphocytic leukemia and comparison with MD Anderson Cancer Center model. Eur J Haematol. 2016;96(1):72-7.

17. International CLLIPIwg. An international prognostic index for patients with chronic lymphocytic leukaemia (CLL-IPI): a meta-analysis of individual patient data. Lancet Oncol. 2016;17(6):779-90.

18. Lad DP, Tejaswi V, Jindal N, Malhotra P, Khadwal A, Prakash G, Jain A, Sreedharanunni S, Sachdeva MS, Naseem S, et al. Modified CLL international prognostic index (CLL-LIPI) using lymphocyte doubling time (LDT) in place of IgHV mutation status in resource-limited settings predicts time to first treatment and overall survival. Leuk Lymphoma. 2020;61(6):1512-15.

19. Soumerai JD, Ni A, Xing G, Huang J, Furman RR, Jones J, Sharman JP, Hallek $M$, Adewoye $\mathrm{AH}$, Dubowy $\mathrm{R}$, et al. Evaluation of the CLL-IPI in relapsed and refractory chronic lymphocytic leukemia in idelalisib phase-3 trials. Leuk Lymphoma. 2019;60(6):1438-46.

20. Soumerai JD, Ni A, Darif M, Londhe A, Xing G, Mun Y, Kay NE, Shanafelt TD, Rabe KG, Byrd JC, et al. Prognostic risk score for patients with relapsed or refractory chronic lymphocytic leukaemia treated with targeted therapies or chemoimmunotherapy: a retrospective, pooled cohort study with external validations. Lancet Haematol. 2019;6(7):e366-74.

21. Hoechstetter MA, Busch R, Eichhorst B, Buhler A, Winkler D, Bahlo J, Robrecht S, Eckart MJ, Vehling-Kaiser U, Jacobs G, et al. Prognostic model for newly diagnosed CLL patients in Binet stage a: results of the multicenter, prospective CLL1 trial of the German CLL study group. Leukemia. 2020;34(4):1038-51. 
22. Magnac C, Porcher R, Davi F, Nataf J, Payelle-Brogard B, Tang RP, Oppezzo P, Lévy V, Dighiero G, Ajchenbaum-Cymbalista F. Predictive value of serum thymidine kinase level for lg-V mutational status in B-CLL. Leukemia. 2003; 17(1):133-7.

23. Pratt G, Thomas P, Marden N, Alexander D, Davis Z, Hussey D, Parry H, Harding $\mathrm{S}$, Catovsky D, Begley J, et al. Evaluation of serum markers in the LRF CLL4 trial: $\beta 2$-microglobulin but not serum free light chains, is an independent marker of overall survival. Leuk Lymphoma. 2016;57(10):2342-50.

24. Autore F, Strati P, Innocenti I, Corrente F, Trentin L, Cortelezzi A, Visco C, Coscia M, Cuneo A, Gozzetti A, et al. Elevated lactate dehydrogenase has prognostic relevance in treatment-naive patients affected by chronic lymphocytic leukemia with triso my 12. Cancers. 2019;11(7):896.

25. Wang HQ, Jia L, Li YT, Farren T, Agrawal SG, Liu FT. Increased autocrine interleukin-6 production is significantly associated with worse clinical outcome in patients with chronic lymphocytic leukemia. J Cell Physiol. 2019; 234(8):13994-4006.

26. Labib HA, Hassanein M, Etewa RL. Serum copper is a simple but valuable prognostic marker in B-cell chronic lymphocytic leukemia. Int J Hematol. 2014;100(6):575-81.

27. Sarris K, Maltezas D, Koulieris E, Bartzis V, Tzenou T, Sachanas S, Nikolaou E, Efthymiou A, Bitsani K, Dimou M, et al. Prognostic significance of serum free light chains in chronic lymphocytic leukemia. Adv Hematol. 2013;2013: 359071.

28. Prieto D, Seija N, Uriepero A, Souto-Padron T, Oliver C, Irigoin V, Guillermo C, Navarrete MA, Inés Landoni A, Dighiero G, et al. LPL protein in chronic lymphocytic Leukaemia have different origins in mutated and Unmutated patients. Advances for a new prognostic marker in CLL. Br J Haematol. 2018; 182(4):521-5.

29. Herishanu Y, Polliack A, Shenhar-Tsarfaty S, Weinberger R, Gelman R, Ziv-Baran T, Zeltser D, Shapira I, Berliner S, Rogowski O. Increased serum C-reactive protein levels are associated with shorter survival and development of second cancers in chronic lymphocytic leukemia. Ann Med. 2017;49(1):75-82.

30. Berke Menteşe I, Yegin ZA, Gökçen S, Özkurt ZN, Yağcı M. Prognostic significance of serum BAFF, APRIL, TACI and BCMA levels in chronic lymphocytic leukemia. Indian J Hematol Blood Transfus. 2019;35(2):265-71.

31. Mulazzani M, Huber M, Borchard S, Langer S, Angele B, Schuh E, Meinl E, Dreyling M, Birnbaum T, Straube A, et al. APRIL and BAFF: novel biomarkers for central nervous system lymphoma. J Hematol Oncol. 2019;12(1):102.

32. Chartomatsidou E, Ntoufa S, Kotta K, Rovida A, Akritidou MA, Belloni D, Ferrero E, Trangas T, Stavroyianni N, Anagnostopoulos A, et al. Inhibition of $\mathrm{EZH} 2$ and immune signaling exerts synergistic antitumor effects in chronic lymphocytic leukemia. Blood Adv. 2019;3(12):1891-6.

33. Li B, Chng WJ. EZH2 abnormalities in lymphoid malignancies: underlying mechanisms and therapeutic implications. J Hematol Oncol. 2019;12(1):118.

34. Damle RN, Wasil T, Fais F, Ghiotto F, Valetto A, Allen SL, Buchbinder A, Budman D, Dittmar K, Kolitz J, et al. Ig V gene mutation status and CD38 expression as novel prognostic indicators in chronic lymphocytic leukemia. Blood. 1999;94(6):1840-7.

35. Molica S, Giannarelli D, Levato L, Gentile M, Mirabelli R, Morabito F. Do biologic parameters affect the time to first treatment of clinical monoclonal B-cell lymphocytosis and chronic lymphocytic leukemia Rai stage 0? Results of a prospective analysis. Clin Lymphoma Myeloma Leuk. 2015;15(3):e55-60.

36. Vosoughi T, Bagheri $M$, Hosseinzadeh $M$, Ehsanpour A, Davari N, Saki N. CD markers variations in chronic lymphocytic leukemia: new insights into prognosis. J Cell Physiol. 2019;234(11):19420-39.

37. Falay M, Ceran F, Gunes AK, Dagdas S, Ayli M, Ozet G. CD38 expression and variation as a prognostic factor chronic lymphocytic leukemia. Clin Lab. 2016;62(7):1287-93.

38. Parikh SA, Shanafelt TD. Risk factors for Richter syndrome in chronic lymphocytic leukemia. Curr Hematol Malig Rep. 2014;9(3):294-9.

39. Wiestner A. Flow cytometry for ZAP-70: new colors for chronic lymphocytic leukemia. Cytometry B Clin Cytom. 2006;70(4):201-3.

40. Amaya-Chanaga Cl, Rassenti LZ. Biomarkers in chronic lymphocytic leukemia: clinical applications and prognostic markers. Best Pract Res Clin Haematol. 2016;29(1):79-89.

41. Tissino E, Pozzo F, Benedetti D, Caldana C, Bittolo T, Rossi FM, Bomben R, Nanni P, Chivilò H, Cattarossi I, et al. CD49d promotes disease progression in chronic lymphocytic leukemia: new insights from CD49d bimodal expression. Blood. 2020;135(15):1244-54.

42. Matuszak M, Lewandowski K, Czyż A, Kiernicka-Parulska J, PrzybyłowiczChalecka A, Jarmuż-Szymczak M, Lewandowska M, Komarnicki M. The prognostic significance of surface dipeptidylpeptidase IV (CD26) expression in B-cell chronic lymphocytic leukemia. Leuk Res. 2016;47:166-71.

43. Chen C, Zhao S, Karnad A, Freeman JW. The biology and role of CD44 in cancer progression: therapeutic implications. J Hematol Oncol. 2018;11(1):64

44. Rozovski U, Keating MJ, Estrov Z. Why is the immunoglobulin heavy chain gene mutation status a prognostic Indicator in chronic lymphocytic leukemia? Acta Haematol. 2018;140(1):51-4.

45. Hamblin TJ, Davis Z, Gardiner A, Oscier DG, Stevenson FK. Unmutated Ig $\mathrm{V}(\mathrm{H})$ genes are associated with a more aggressive form of chronic lymphocytic leukemia. Blood. 1999;94(6):1848-54.

46. Kröber A, Seiler T, Benner A, Bullinger L, Brückle E, Lichter P, Döhner H, Stilgenbauer S. V(H) mutation status, CD38 expression level, genomic aberrations, and survival in chronic lymphocytic leukemia. Blood. 2002; 100(4):1410-6.

47. Hu B, Patel KP, Chen HC, Wang X, Luthra R, Routbort MJ, Kanagal-Shamanna $R$, Medeiros $L$, Yin CC, Zuo Z, et al. Association of gene mutations with time-to-first treatment in 384 treatment-naive chronic lymphocytic leukaemia patients. Br J Haematol. 2019;187(3):307-18.

48. Hamblin TJ, Orchard JA, Gardiner A, Oscier DG, Davis Z, Stevenson FK. Immunoglobulin $V$ genes and CD38 expression in CLL. Blood. 2000;95(7):2455-7.

49. Eladl E, Tremblay-LeMay R, Rastgoo N, Musani R, Chen W, Liu A, Chang H. Role of CD47 in hematological malignancies. J Hematol Oncol. 2020; 13(1):96.

50. Sandoval-Sus JD, Chavez JC, Dalia S, Naqvi SMH, Talati C, Nodzon L, KharfanDabaja MA, Pinilla-lbarz J. Association between immunoglobulin heavychain variable region mutational status and isolated favorable baseline genomic aberrations in chronic lymphocytic leukemia. Leuk Lymphoma. 2018:59(1):59-68.

51. Jaramillo S, Agathangelidis A, Schneider C, Bahlo J, Robrecht S, Tausch E, Bloehdorn J, Hoechstetter M, Fischer K, Eichhorst B, et al. Prognostic impact of prevalent chronic lymphocytic leukemia stereotyped subsets: analysis within prospective clinical trials of the German CLL study group (GCLLSG). Haematologica. 2019. https://doi.org/10.3324/haematol.2019.231027.

52. Shea LK, Honjo K, Redden DT, Tabengwa E, Li R, Li FJ, Shakhmatov M, Chiorazzi N, Davis RS. Fc receptor-like 2 (FCRL2) is a novel marker of low-risk $\mathrm{CLL}$ and refines prognostication based on IGHV mutation status. Blood Cancer J. 2019;9(6):47.

53. Seymour EK, Ruterbusch JJ, Beebe-Dimmer JL, Schiffer CA. Real-world testing and treatment patterns in chronic lymphocytic leukemia: a SEER patterns of care analysis. Cancer. 2019;125(1):135-43.

54. Döhner $H$, Stilgenbauer $S$, Benner A, Leupolt E, Kröber A, Bullinger L, Döhner K, Bentz M, Lichter P. Genomic aberrations and survival in chronic lymphocytic leukemia. N Engl J Med. 2000;343(26):1910-6.

55. Tari K, Shamsi Z, Reza Ghafari H, Atashi A, Shahjahani M, Abroun S. The role of the genetic abnormalities, epigenetic and microRNA in the prognosis of chronic lymphocytic leukemia. Exp Oncol. 2018;40(4):261-7.

56. Huang SJ, Gillan TL, Gerrie AS, Hrynchak M, Karsan A, Ramadan K, Smith AC, Toze CL, Bruyere $\mathrm{H}$. Influence of clone and deletion size on outcome in chronic lymphocytic leukemia patients with an isolated deletion $13 \mathrm{q}$ in a population-based analysis in British Columbia, Canada. Genes Chromosomes Cancer. 2016:55(1):16-24.

57. Puiggros A, Venturas M, Salido M, Blanco G, Fernandez-Rodriguez C, Collado R, Valiente A, Ruiz-Xivillé N, Carrió A, Ortuño FJ, et al. Interstitial 13q14 deletions detected in the karyotype and translocations with concomitant deletion at 13q14 in chronic lymphocytic leukemia: different genetic mechanisms but equivalent poorer clinical outcome. Genes Chromosomes Cancer. 2014;53(9):788-97.

58. Bagacean C, Le Dantec C, Berthou C, Tempescul A, Saad H, Bordron A, Zdrenghea M, Cristea V, Douet-Guilbert N, Renaudineau Y. Combining cytogenetic and epigenetic approaches in chronic lymphocytic leukemia improves prognosis prediction for patients with isolated $13 q$ deletion. Clin Epigenetics. 2017;9:122.

59. González-Gascón YMI, Hernández-Sánchez M, Rodríguez-Vicente AE, Sanzo C, Aventín A, Puiggros A, Collado R, Heras C, Muñoz C, Delgado J, et al. A high proportion of cells carrying trisomy 12 is associated with a worse outcome in patients with chronic lymphocytic leukemia. Hematol Oncol. 2016;34(2):84-92.

60. Baliakas P, Puiggros A, Xochelli A, Sutton LA, Nguyen-Khac F, Gardiner A, Plevova K, Minga E, Hadzidimitriou A, Walewska R, et al. Additional trisomies amongst patients with chronic lymphocytic leukemia carrying trisomy 12 : the accompanying chromosome makes a difference. Haematologica. 2016; 101(7):e299-302. 
61. Roos-Weil D, Nguyen-Khac F, Chevret S, Touzeau C, Roux C, Lejeune J, Cosson A, Mathis S, Feugier P, Leprêtre S, et al. Mutational and cytogenetic analyses of $188 \mathrm{CLL}$ patients with trisomy 12: a retrospective study from the French innovative leukemia organization (FILO) working group. Genes Chromosomes Cancer. 2018;57(11):533-40.

62. Goy J, Gillan TL, Bruyere H, Huang SJT, Hrynchak M, Karsan A, Ramadan K, Connors J, Toze CL, Gerrie AS. Chronic lymphocytic leukemia patients with deletion 11q have a short time to requirement of first-line therapy, but long overall survival: results of a population-based cohort in British Columbia, Canada. Clin Lymphoma Myeloma Leuk. 2017;17(6):382-9.

63. Hernández J, Hernández-Sánchez M, Rodríguez-Vicente AE, Grossmann V, Collado R, Heras C, Puiggros A, Martín A, Puig N, Benito R, et al. A low frequency of losses in $11 \mathrm{q}$ chromosome is associated with better outcome and lower rate of genomic mutations in patients with chronic lymphocytic leukemia. PLoS One. 2015;10(11):e0143073.

64. Chavez JC, Kharfan-Dabaja MA, Kim J, Yue B, Dalia S, Pinilla-lbarz J, Anasetti C, Locke FL. Genomic aberrations deletion 11q and deletion 17p independently predict for worse progression-free and overall survival after allogeneic hematopoietic cell transplantation for chronic lymphocytic leukemia. Leuk Res. 2014;38(10):1165-72.

65. Bagacean C, Tempescul A, Ternant D, Banet A, Douet-Guilbert N, Bordron A, Bendaoud B, Saad H, Zdrenghea M, Berthou C, et al. 17p deletion strongly influences rituximab elimination in chronic lymphocytic leukemia. J Immunother Cancer. 2019;7(1):22.

66. Yuan YY, Zhu HY, Wu JZ, Xia Y, Liang JH, Wu W, Cao L, Wang L, Fan L, Li JY, et al. The percentage of cells with $17 p$ deletion and the size of $17 p$ deletion subclones show prognostic significance in chronic lymphocytic leukemia. Genes Chromosomes Cancer. 2019;58(1):43-51.

67. Yeung CCS, Shadman M. How to choose the best treatment and testing for chronic lymphocytic leukemia in the tsunami of new treatment options. Curr Oncol Rep. 2019;21(8):74.

68. Juliusson G, Oscier DG, Fitchett M, Ross FM, Stockdill G, Mackie MJ, Parker AC, Castoldi GL, Guneo A, Knuutila S, et al. Prognostic subgroups in B-cell chronic lymphocytic leukemia defined by specific chromosomal abnormalities. N Engl J Med. 1990;323(11):720-4.

69. Baliakas P, Iskas M, Gardiner A, Davis Z, Plevova K, Nguyen-Khac F, Malcikova J, Anagnostopoulos A, Glide S, Mould S, et al. Chromosomal translocations and karyotype complexity in chronic lymphocytic leukemia: a systematic reappraisal of classic cytogenetic data. Am J Hematol. 2014;89(3):249-55.

70. Baliakas P, Jeromin S, Iskas M, Puiggros A, Plevova K, Nguyen-Khac F, Davis Z, Rigolin GM, Visentin A, Xochelli A, et al. Cytogenetic complexity in chronic lymphocytic leukemia: definitions, associations, and clinical impact. Blood. 2019:133(11):1205-16.

71. Rigolin GM, Saccenti E, Bassi C, Lupini L, Quaglia FM, Cavallari M, Martinelli S, Formigaro L, Lista E, Bardi MA, et al. Extensive next-generation sequencing analysis in chronic lymphocytic leukemia at diagnosis: clinical and biological correlations. J Hematol Oncol. 2016;9(1):88.

72. Landau DA, Tausch E, Taylor-Weiner AN, Stewart C, Reiter JG, Bahlo J, Kluth S, Bozic I, Lawrence M, Böttcher S, et al. Mutations driving CLL and their evolution in progression and relapse. Nature. 2015;526(7574):525-30.

73. Bosch F, Dalla-Favera R. Chronic lymphocytic leukaemia: from genetics to treatment. Nat Rev Clin Oncol. 2019;16(11):684-701.

74. Austen B, Skowronska A, Baker C, Powell JE, Gardiner A, Oscier D, Majid A, Dyer M, Siebert R, Taylor AM, et al. Mutation status of the residual ATM allele is an important determinant of the cellular response to chemotherapy and survival in patients with chronic lymphocytic leukemia containing an 11q deletion. J Clin Oncol. 2007;25(34):5448-57.

75. Nabhan C, Raca G, Wang YL. Predicting prognosis in chronic lymphocytic leukemia in the contemporary era. JAMA oncology. 2015;1(7):965-74.

76. Cohen JA, Bomben R, Pozzo F, Tissino E, Härzschel A, Hartmann TN, Zucchetto A, Gattei V. An updated perspective on current prognostic and predictive biomarkers in chronic lymphocytic leukemia in the context of chemoimmunotherapy and novel targeted therapy. Cancers. 2020;12(4):894.

77. Zhang Y, Zhou X, Li Y, Xu Y, Lu K, Li P, Wang X. Inhibition of maternal embryonic leucine zipper kinase with OTSSP167 displays potent antileukemic effects in chronic lymphocytic leukemia. Oncogene. 2018;37(41): 5520-33.

78. Quijada-Álamo M, Hernández-Sánchez M, Robledo C, Hernández-Sánchez JM, Benito R, Montaño A, Rodríguez-Vicente AE, Quwaider D, Martín A, García-Álvarez M, et al. Next-generation sequencing and FISH studies reveal the appearance of gene mutations and chromosomal abnormalities in hematopoietic progenitors in chronic lymphocytic leukemia. J Hematol Oncol. 2017;10(1):83

79. Plesingerova H, Librova Z, Plevova K, Libra A, Tichy B, Skuhrova Francova H, Vrbacky F, Smolej L, Mayer J, Bryja V, et al. COBLL1, LPL and ZAP70 expression defines prognostic subgroups of chronic lymphocytic leukemia patients with high accuracy and correlates with IGHV mutational status. Leuk Lymphoma. 2017;58(1):70-9.

80. Ramassone A, D'Argenio A, Veronese A, Basti A, Soliman SHA, Volinia S, Bassi C, Pagotto S, Ferracin M, Lupini L, et al. Genetic dynamics in untreated CLL patients with either stable or progressive disease: a longitudinal study. J Hematol Oncol. 2019;12(1):114.

81. Farahat NMG, Elkaffash D, Alghandour AH, Swelem RS, Abo El-Wafa RAH. Study of microRNA profile as a molecular biomarker in Egyptian chronic lymphocytic leukemia. Indian J Hematol Blood Transfus. 2019;35(1):89-99.

82. Calin GA, Ferracin M, Cimmino A, Di Leva G, Shimizu M, Wojcik SE, lorio MV, Visone R, Sever NI, Fabbri M, et al. A MicroRNA signature associated with prognosis and progression in chronic lymphocytic leukemia. N Engl J Med. 2005;353(17):1793-801.

83. Yi M, Xu L, Jiao Y, Luo S, Li A, Wu K. The role of cancer-derived microRNAs in cancer immune escape. J Hematol Oncol. 2020;13(1):25.

84. Balatti V, Pekarky Y, Croce CM. Role of microRNA in chronic lymphocytic leukemia onset and progression. J Hematol Oncol. 2015;8:12.

85. Pepe F, Balatti V. Role of non-coding RNAs in the development of targeted therapy and immunotherapy approaches for chronic lymphocytic leukemia. J Clin Med. 2020;9(2):593.

86. Buhagiar A, Borg J, Ayers D. Overview of current microRNA biomarker signatures as potential diagnostic tools for leukaemic conditions. Noncoding RNA Res. 2020;5(1):22-6.

87. Casabonne D, Benavente $Y$, Seifert J, Costas L, Armesto M, Arestin M, Besson C, Hosnijeh FS, Duell EJ, Weiderpass E, et al. Serum levels of hsa-miR-16-5p, hsa-miR-29a-3p, hsa-miR-150-5p, hsa-miR-155-5p and hsa-miR-223-3p and subsequent risk of chronic lymphocytic leukemia in the EPIC study. Int J Cancer. 2020;147(5):1315-24.

88. Wong KY, Yim RL, Kwong YL, Leung CY, Hui PK, Cheung F, Liang R, Jin DY, Chim CS. Epigenetic inactivation of the MIR129-2 in hematological malignancies. J Hematol Oncol. 2013;6:16.

89. Li Y, Mao M, Liu H, Wang X, Kou Z, Nie Y, Wang Y, Wang Z, Huang Q, Lang T, et al. miR-34a and miR-29b as indicators for prognosis of treatment-free survival of chronic lymphocytic leukemia patients in Chinese Uygur and Han populations. Mol Cell Probes. 2019;47:101436.

90. Wong NK, Huang CL, Islam R, Yip SP. Long non-coding RNAs in hematological malignancies: translating basic techniques into diagnostic and therapeutic strategies. J Hematol Oncol. 2018;11(1):131.

91. Katsaraki K, Artemaki PI, Papageorgiou SG, Pappa V, Scorilas A, Kontos CK. Identification of a novel, internal tRNA-derived RNA fragment as a new prognostic and screening biomarker in chronic lymphocytic leukemia, using an innovative quantitative real-time PCR assay. Leuk Res. 2019;87:106234.

92. Pozzo F, Bittolo T, Arruga F, Bulian P, Macor P, Tissino E, Gizdic B, Rossi FM, Bomben R, Zucchetto A, et al. NOTCH1 mutations associate with low CD20 level in chronic lymphocytic leukemia: evidence for a NOTCH1 mutationdriven epigenetic dysregulation. Leukemia. 2016;30(1):182-9.

93. Binet JL, Auquier A, Dighiero G, Chastang C, Piguet H, Goasquen J, Vaugier G, Potron G, Colona P, Oberling F, et al. A new prognostic classification of chronic lymphocytic leukemia derived from a multivariate survival analysis. Cancer. 1981;48(1):198-206.

94. Rai KR, Sawitsky A, Cronkite EP, Chanana AD, Levy RN, Pasternack BS. Clinical staging of chronic lymphocytic leukemia. Blood. 1975;46(2):219-34.

95. Zengin N, Kars A, Kansu E, Özdemir O, Barişta I, Güllü I, Güler N, Özişik Y, Dündar S, Firat D. Comparison of Rai and Binet Classifications in Chronic Lymphocytic Leukemia. Hematology (Amsterdam, Netherlands). 1997;2(2): 125-9.

96. Pflug N, Bahlo J, Shanafelt TD, Eichhorst BF, Bergmann MA, Elter T, Bauer K, Malchau G, Rabe KG, Stilgenbauer S, et al. Development of a comprehensive prognostic index for patients with chronic lymphocytic leukemia. Blood. 2014;124(1):49-62.

97. International CLL-IPI working group. An international prognostic index for patients with chronic lymphocytic leukaemia (CLL-IPI): a meta-analysis of individual patient data. Lancet Oncol. 2016;17(6):77-90.

98. Gentile M, Shanafelt TD, Rossi D, Laurenti L, Mauro FR, Molica S, Cutrona G, Uccello G, Campanelli M, Vigna E, et al. Validation of the CLL-IPI and 
comparison with the MDACC prognostic index in newly diagnosed patients. Blood. 2016;128(16):2093-5.

99. Molica S, Shanafelt TD, Giannarelli D, Gentile M, Mirabelli R, Cutrona G, Levato L, Di Renzo N, Di Raimondo F, Musolino C, et al. The chronic lymphocytic leukemia international prognostic index predicts time to first treatment in early CLL: independent validation in a prospective cohort of early stage patients. Am J Hematol. 2016;91(11):1090-5.

100. Gentile M, Shanafelt TD, Mauro FR, Reda G, Rossi D, Laurenti L, Del Principe MI, Cutrona G, Angeletti I, Coscia M, et al. Predictive value of the CLL-IPI in CLL patients receiving chemo-immunotherapy as first-line treatment. Eur $J$ Haematol. 2018;101(5):703-6.

101. Muñoz-Novas C, Poza-Santaella M, González-Gascón YMI, HernándezSánchez M, Rodríguez-Vicente AE, Infante MS, Heras C, Foncillas M, Marín K, Hernández-Rivas JM, et al. The International Prognostic Index for Patients with Chronic Lymphocytic Leukemia Has the Higher Value in Predicting Overall Outcome Compared with the Barcelona-Brno Biomarkers Only Prognostic Model and the MD Anderson Cancer Center Prognostic Index. Biomed Res Int. 2018;2018:9506979.

102. Brown JR, Kim HT, Armand P, Cutler C, Fisher DC, Ho V, Koreth J, Ritz J, Wu C, Antin JH, et al. Long-term follow-up of reduced-intensity allogeneic stem cell transplantation for chronic lymphocytic leukemia: prognostic model to predict outcome. Leukemia. 2013;27(2):362-9.

103. Delgado J, Doubek M, Baumann T, Kotaskova J, Molica S, Mozas P, RivasDelgado A, Morabito F, Pospisilova S, Montserrat E. Chronic lymphocytic leukemia: a prognostic model comprising only two biomarkers (IGHV mutational status and FISH cytogenetics) separates patients with different outcome and simplifies the CLL-IPI. Am J Hematol. 2017;92(4):375-80.

104. Tadmor T, Braester A, Najib D, Aviv A, Herishanu Y, Yuklea M, Shvidel L, Rahimi-Levene N, Ruchlemer R, Arad A, et al. A new risk model to predict time to first treatment in chronic lymphocytic leukemia based on heavy chain immunoparesis and summated free light chain. Eur J Haematol. 2019; 103(4):335-41.

105. Lu K, Wang X. Therapeutic advancement of chronic lymphocytic leukemia. J Hematol Oncol. 2012;5:55.

106. Xu W, Yang S, Zhou K, Pan L, Li Z, Zhou J, Gao S, Zhou D, Hu J, Feng R, et al. Treatment of relapsed/refractory chronic lymphocytic leukemia/small lymphocytic lymphoma with the BTK inhibitor zanubrutinib: phase 2, singlearm, multicenter study. J Hematol Oncol. 2020;13(1):48.

107. Ayyappan S, Maddocks K. Novel and emerging therapies for B cell lymphoma. J Hematol Oncol. 2019;12(1):82.

108. Italiano A, Soria JC, Toulmonde M, Michot JM, Lucchesi C, Varga A, Coindre JM, Blakemore SJ, Clawson A, Suttle B, et al. Tazemetostat, an EZH2 inhibitor, in relapsed or refractory B-cell non-Hodgkin lymphoma and advanced solid tumours: a first-in-human, open-label, phase 1 study. Lancet Oncol. 2018;19(5):649-59.

109. Tremblay-LeMay R, Rastgoo N, Pourabdollah M, Chang H. EZH2 as a therapeutic target for multiple myeloma and other haematological malignancies. Biomarker Res. 2018;6:34.

110. Molica S, Giannarelli D, Mirabelli R, Levato L, Shanafelt TD. The magnitude of improvement in progression-free survival with targeted therapy in relapsed/ refractory chronic lymphocytic leukemia based on prognostic risk category: a systematic review and meta-analysis. Leuk Lymphoma. 2019;60(7):1644-9.

111. Kittai AS, Lunning M, Danilov AV. Relevance of prognostic factors in the era of targeted therapies in CLL. Curr Hematol Malig Rep. 2019;14(4):302-9.

112. Eichhorst B, Hallek M. Prognostication of chronic lymphocytic leukemia in the era of new agents. Hematol Am Soc Hematol Educ Program. 2016;2016(1):149-55.

113. Tausch E, Schneider C, Robrecht S, Zhang C, Dolnik A, Bloehdorn J, Bahlo J, Al-Sawaf O, Ritgen M, Fink AM, et al. Prognostic and predictive impact of genetic markers in patients with CLL treated with obinutuzumab and venetoclax. Blood. 2020;135(26):2402-12.

114. Tissino E, Benedetti D, Herman SEM, Ten Hacken E, Ahn IE, Chaffee KG, Rossi FM, Dal Bo M, Bulian P, Bomben R, et al. Functional and clinical relevance of VLA-4 (CD49d/CD29) in ibrutinib-treated chronic lymphocytic leukemia. J Exp Med. 2018;215(2):681-97.

115. Böttcher S, Ritgen M, Fischer K, Stilgenbauer S, Busch RM, Fingerle-Rowson G, Fink AM, Bühler A, Zenz T, Wenger MK, et al. Minimal residual disease quantification is an independent predictor of progression-free and overall survival in chronic lymphocytic leukemia: a multivariate analysis from the randomized GCLLSG CLL8 trial. J Clin Oncol. 2012;30(9):980-8.
116. Thompson M, Brander D, Nabhan C, Mato A. Minimal residual disease in chronic lymphocytic leukemia in the era of novel agents: a review. JAMA Oncol. 2018;4(3):394-400.

\section{Publisher's Note}

Springer Nature remains neutral with regard to jurisdictional claims in published maps and institutional affiliations.

\section{Ready to submit your research? Choose BMC and benefit from:}

- fast, convenient online submission

- thorough peer review by experienced researchers in your field

- rapid publication on acceptance

- support for research data, including large and complex data types

- gold Open Access which fosters wider collaboration and increased citations

- maximum visibility for your research: over $100 \mathrm{M}$ website views per year

At BMC, research is always in progress.

Learn more biomedcentral.com/submissions 